\title{
DETECTION OF H. PYLORI IN GASTRIC BIOPSIES: A COST EFFECTIVE METHOD FOR DEVELOPING COUNTRIES.
}

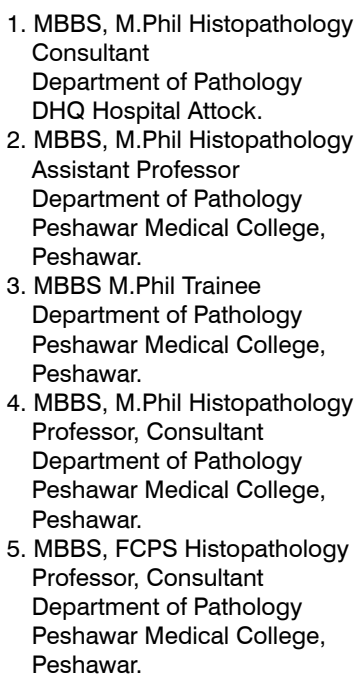

Correspondence Address:

Dr. Hina Khan

Officers Mess, E9/2, Sqn Idr Ahtisham Ali, PAF base kamra, Attock.

Article received on:

29/09/2018

Accepted for publication:

15/03/2019

Received after proof reading:

31/07/2019

\section{INTRODUCTION}

Chronic gastritis has remained an underrated disease despite millions of deaths worldwide occurring from its sequel like peptic ulcer and gastric cancer. ${ }^{1}$ Researches on pathogenesis of gastritis gained popularity after the discovery of bacterium Helicobacter pylori $(\mathrm{H}$. pylori) by Marshall and Warren in 1982 which resulted in a paradigm shift in the understanding of gastric diseases. ${ }^{2}$

H. pylori are small, highly motile, microaerophilic, gram negative, campylobacter like organisms, well known to be the most common human infection worldwide. ${ }^{3}$ Chronic gastritis is prevalent in approximately $50 \%$ of world population. ${ }^{4}$ In Pakistan the frequency of $\mathrm{H}$. pylori was found to be $88.3 \% .^{5}$

H. pylori is involved in the etiology of peptic ulcer, gastric adenocarcinoma and Mucosa Associated Lymphoid Tissue Lymphoma (MALTOMA). ${ }^{6,7}$ WHO labeled $\mathrm{H}$. pylori as a Class 1 carcinogen in 1994, which gave a whole new perspective to the understanding of gastric carcinogenesis.

Although routine H\&E stained sections are sufficient to detect $\mathrm{H}$. pylori ${ }^{8}$ but in cases of atrophic mucosa and post eradication therapy ancillary stains may be required due to low bacterial count. ${ }^{9} \mathrm{HC}$ technique uses the principle of antigen binding to specific antibodies in tissue. Antigen-antibody complexes are visualized by conjugation of peroxidase enzyme to the antibody and by tagging the antibody to a fluorophore (rhodamine, fluorescein). According to Ju Yup Lee et al H\&E and Giemsa are adequate for an accurate diagnosis of $\mathrm{H}$. pylori ${ }^{9}$ but Razaiye $\mathrm{T}$ et al quoted that IHC has been found to be superior to other histochemical stains in false negative $\mathrm{H}$. 
pylori gastritis. ${ }^{10}$

The aim of this study is to assess the reliability and cost effectiveness of H\&E for developing countries and compare it with $\mathrm{IHC}$ as gold standard for the detection of $\mathrm{H}$. pylori in gastric biopsies.

\section{MATERIALS AND METHODS}

This descriptive cross-sectional study included endoscopic gastric biopsies of 50 consecutive patients with dyspeptic symptoms who presented to OPD of Kuwait Teaching Hospital and Mercy Teaching Hospital, Peshawar from April 2017 to December 2017. Patient's profile, signs/symptoms, history of NSAID and Proton Pump Inhibitors (PPI) intake were noted on a predesigned proforma. The study was approved by the Ethical Review Board of Peshawar Medical College.

Biopsy punches were taken according to the Updated Sydney Protocol (USP), with two biopsy punches from Antrum and Corpus each and one punch from incisura angularis. Biopsies were fixed in $10 \%$ Buffered formalin and sent to Histopathology Laboratory, Peshawar Medical College. Patients with incomplete information and biopsies with autolytic changes were excluded due to antigen retrieval problem. Gastric biopsies were routinely processed. Two slides were kept for immunohistochemistry and one as reserve. Slides were observed on 100X power to enhance the probability of finding $\mathrm{H}$. pylori. The histological features were recorded according to USP.

Immunohistochemistry was performed at Histopathology Diagnostic Laboratory, Peshawar Medical College. Peshawar, using Polyclonal Rabbit Anti-Helicobacter Pylori antibody. Hot air oven method was used for Antigen retrieval. Controls were used for comparison while assessing the slides.

The data was entered and analyzed in SPSS version 19. For continuous variables mean was calculated. For categorical variables frequency and percentages were calculated. Sensitivity, specificity, positive predictive value, and negative predictive value were calculated for $H \& E$. Chi square test was used for calculating $p$ value. A value less than or equal to 0.05 was considered statistically significant.

\section{RESULTS}

A total of 50 patients with dyspeptic symptoms undergoing endoscopic biopsy were included in this study. Among these 50 cases of gastric biopsies 24 (48\%) were males and 26 (52\%) were females. Male to female ratio was 1:1.1 (Table-I). The present study showed majority of females (61.1\%) being $\mathrm{H}$. pylori positive in comparison with males (53.1\%).

The age ranged from 11-70 years with a mean of 40 years. Maximum number of $\mathrm{H}$. pylori positivity was seen in the extreme of ages, $100 \%$ in the age group 61-80 $(n=2 / 2)$ years and $66 \%(n=2 / 3)$ in the age group $01-20$ years. It was followed by $65 \%$ $(n=13 / 20)$ in the age group $41-60$ years and $60 \%$ $(n=15 / 25)$ in the age group $21-40$ years (Table-II).

The most common presenting symptom was epigastric pain, nausea/vomiting and bloating/ burping. Amongst the 45 patients with epigastric pain $28(62.2 \%)$ were positive for $H$. pylori by $\mathrm{IHC}$ and $17(34 \%)$ by H\&E. The least common symptom was hematemesis and melena were present in 5 of patients, 4 (80\%) of which were positive for $\mathrm{H}$. pylori by $\mathrm{IHC}$ and 2 (40\%) by $\mathrm{H} \& \mathrm{E}$ (Table-III). No significant association was found between a particular symptom and $\mathrm{H}$. pylori positivity.

The cases were diagnosed according to the USP. Mild chronic inflammation was found in 25 (50\%) cases, whereas moderate chronic inflammation in $22(44 \%)$ and severe chronic inflammation in 3 $(6 \%)$ of the cases (Table-IV).

According to the severity of inflammation, the staining ability of H\&E and IHC showed that 13 out of 25 cases of Mild Chronic Inflammation were positive for $\mathrm{H}$. pylori by $\mathrm{IHC}$ and only 4 by $\mathrm{H} \& \mathrm{E}$ with 9 cases as false negative. Among the 22 cases with Moderate Chronic Inflammation, 16 were $\mathrm{H}$. pylori positive on $\mathrm{IHC}$ and 10 on $\mathrm{H} \& \mathrm{E}$ with 5 false negative cases. In the three severe chronic 
inflammation cases, H. pylori was diagnosed by $\mathrm{IHC}$ in all 3 and only one case was missed by H\&E (Table-V).

In gastric biopsies H\&E was positive for $\mathrm{H}$. pylori in $34 \%$ of cases and negative in $66 \%$. Whereas
IHC showed $64 \%$ cases of $\mathrm{H}$. pylori positive and $36 \%$ as negative. Sensitivity of H\&E was $46.8 \%$ and specificity was $88.8 \%$. Positive predictive value of $\mathrm{H} \& \mathrm{E}$ was $88.2 \%$ and negative predictive value was $48.5 \%$ (Table-VI).

\begin{tabular}{|c|c|c|c|c|}
\hline \multirow{2}{*}{ Gender } & \multicolumn{2}{|c|}{ H\&E } & \multicolumn{2}{|c|}{ IHC } \\
\hline & Absent & Present & Absent & Present \\
\hline \multirow{2}{*}{ Male } & 15 & 9 & 7 & 17 \\
\hline & $(30.0 \%)$ & $(18.0 \%)$ & $(14 \%)$ & $(34 \%)$ \\
\hline \multirow{2}{*}{ Female } & 18 & 8 & 11 & 15 \\
\hline & $(36.0 \%)$ & $(16.0 \%)$ & $(22 \%)$ & $(30 \%)$ \\
\hline \multirow{2}{*}{ Total } & 33 & 17 & 18 & 32 \\
\hline & (66.0\%) & $(34.0 \%)$ & (36\%) & (64\%) \\
\hline \multicolumn{5}{|c|}{ Table-I. Gender distribution of $\mathrm{H}$. pylori positive cases by IHC and H\&E } \\
\hline Age in Years & $\begin{array}{c}\text { H. pylori +ve } \\
n=32(64 \%)\end{array}$ & $\begin{array}{l}\text { H. pylori -ve } \\
n=18(36 \%)\end{array}$ & Total & Percentage \\
\hline $01-20$ & 2 & 1 & 03 & 66 \\
\hline $21-40$ & 15 & 10 & 25 & 60 \\
\hline $41-60$ & 13 & 7 & 20 & 65 \\
\hline $61-80$ & 2 & 0 & 02 & 100 \\
\hline
\end{tabular}

Table-II. Comparison of age in $\mathrm{H}$. pylori IHC positive and negative cases

\begin{tabular}{|l|c|c|c|c|c|}
\hline \multicolumn{2}{|c}{ Signs and Symptoms } & \multicolumn{2}{c|}{ H. Pylori on H\&E } & \multicolumn{2}{c|}{ H. Pylori on IHC } \\
\cline { 2 - 6 } & & $\begin{array}{c}\text { Negative } \\
\mathbf{n}(\%)\end{array}$ & $\begin{array}{c}\text { Positive } \\
\mathbf{n}(\%)\end{array}$ & $\begin{array}{c}\text { Negative } \\
\mathbf{n}(\%)\end{array}$ & $\begin{array}{c}\text { Positive } \\
\mathbf{n}(\%)\end{array}$ \\
\hline \multirow{2}{*}{ Epigastric Pain } & Present & $28(56)$ & $17(34)$ & $17(37.8)$ & $28(62.2)$ \\
\hline \multirow{2}{*}{ Nausea/Vomiting } & Absent & $5(10)$ & $0(0)$ & $1(20)$ & $4(80)$ \\
\hline \multirow{2}{*}{ Hematemesis/Melena } & Present & $22(44)$ & $11(22)$ & $12(36.4)$ & $21(63.6)$ \\
\hline \multirow{2}{*}{ Bloating/Burping } & Absent & $11(22)$ & $6(12)$ & $6(35.3)$ & $11(64.7)$ \\
\hline \multirow{2}{*}{ Dyspepsia } & Present & $3(60)$ & $2(40)$ & $1(20)$ & $4(80)$ \\
\cline { 2 - 6 } & Absent & $30(60)$ & $15(30)$ & $17(37.8)$ & $28(62.2)$ \\
\hline & Present & $8(16)$ & $7(14)$ & $4(26.7)$ & $11(73.3)$ \\
\hline & Absent & $25(50)$ & $10(20)$ & $14(40)$ & $21(60)$ \\
\hline
\end{tabular}

Table-III. Comparison of chronic gastritis signs and symptoms with $\mathrm{H}$. pylori status by IHC and H\&E

\begin{tabular}{|c|c|c|c|c|}
\hline $\begin{array}{c}\text { Chronic } \\
\text { Inflammation }\end{array}$ & Mild & Moderate & Severe & Total \\
\hline Active & $25(5 \%)$ & $22(44 \%)$ & $3(6 \%)$ & $50(100 \%)$ \\
\hline Atrophy & $12(48)$ & $20(90)$ & $3(100)$ & $35(70)$ \\
\hline Intestinal Metaplasia & $8(32)$ & $14(63.6)$ & $3(100)$ & $25(50)$ \\
\hline
\end{tabular}

Table-IV. Histopathological findings according to USP

\begin{tabular}{|l|c|c|c|c|}
\hline \multirow{2}{*}{$\begin{array}{c}\text { Chronic } \\
\text { Inflammation }\end{array}$} & H. pylori -ve & H. pylori +ve & H. pylori -ve & H. pylori +ve \\
\hline Mild & 21 & 4 & 12 & 13 \\
\hline Moderate & 11 & 11 & 6 & 16 \\
\hline Severe & 1 & 2 & 0 & 3 \\
\hline Total n (\%) & $33(66)$ & $17(34)$ & $18(36)$ & $32(64)$ \\
\hline
\end{tabular}

Table-V. Detection of $\mathrm{H}$. pylori using H\&E and IHC according to degree of inflammation 


\begin{tabular}{|l|c|c|c|}
\hline & IHC Positive & IHC Negative & Total \\
\hline H\&E Positive & 15 & 2 & 17 \\
\hline H\&E Negative & 17 & 16 & 33 \\
\hline Total & 32 & 18 & 50
\end{tabular}

Table-VI. Comparison of H. pylori detection by H\&E and IHC

\section{DISCUSSION}

Analysis of patient's characteristics in our study reveals majority of female patients being $\mathrm{H}$. pylori positive with a male to female ratio of 1:1.1. Interestingly, international studies reveal a male predilection for $\mathrm{H}$. pylori infection. ${ }^{12-14}$ The difference may be due to geographical variation, race, genetic diversity and socioeconomic status. ${ }^{15,16}$

According to present study, the mean age of chronic gastritis patients was $39.9 \pm 12.9$ years. Our findings are consistent with a local study by Mehmood et al., in 2010, with 176 sample size showing the mean age of $39.6 \pm 15.2$. However, a study by Awaad et al. in Egypt (2014), with sample size of 100 and a study by Lissa et al. in Brazil (2012), with 94 chronic gastritis patients, showed mean age of gastritis patients as 47 and $48 \pm 16$ years respectively.

In this study maximum number of $\mathrm{H}$. pylori positivity was seen in extreme of ages which is in accordance with other international studies concluding that prevalence of $\mathrm{H}$. pylori increases with age.,17 However, recent studies show a marked reduction in $\mathrm{H}$. pylori infection in the elderly which can be explained by the popularity of eradication therapies. ${ }^{18}$

According to histological diagnosis the current study showed maximum number of cases (50\%) as mild chronic inflammation, followed by moderate chronic inflammation (44\%) and only $03(6 \%)$ as severe chronic inflammation. This was consistent with a national study, where $57.3 \%$ patients had mild inflammation, $42.6 \%$ had moderate chronic inflammation and $4.4 \%$ had severe chronic inflammation. ${ }^{5}$ However in contrast to our findings, a study by Marcela S.B. et al. showed more cases of moderate to severe chronic inflammation (31.5\%) as compared to mild (25.9\%). ${ }^{21}$
The ability of H\&E in diagnosing $H$. pylori according to the degree of inflammation was assessed. Our study showed that H\&E could not be relied upon in cases of mild inflammation because $69.2 \%$ cases were missed by it in this category. However, the ability of H\&E to detect $H$. pylori increased with severity of inflammation which is in accordance with other studies., ${ }^{72}$ In cases of mild inflammation IHC stain detected cases missed by H\&E which is in agreement with a number of past studies. ${ }^{21,23}$

For a developing country like Pakistan, H\&E fulfills the need of a cost-effective and efficient diagnostic tool for $\mathrm{H}$. pylori diagnosis although less accurate than $\mathrm{IHC}^{8,19}$, and in comparative analysis showed a low sensitivity and specificity. ${ }^{24,25}$

\section{CONCLUSION}

Our study concludes that used alone H\&E can easily detect $\mathrm{H}$. pylori in gastric biopsies in most of the cases. However, IHC may be used in selected patients with negative H\&E results and strong clinical suspicion of $\mathrm{H}$. pylori infection.

\section{Copyright $@ 15$ Mar, 2019.}

\section{REFERENCES}

1. Sipponen P, Marshall BJ. Gastritis and gastric cancer: Western countries. Gastroenterology clinics of north America. 2000;29(3):579-92.

2. Marshall B, Warren JR. Unidentified curved bacilli in the stomach of patients with gastritis and peptic ulceration. The Lancet. 1984; 323(8390):1311-5.

3. Bittencourt PF, Rocha GA, Penna FJ, Queiroz DM. Gastroduodenal peptic ulcer and Helicobacter pylori infection in children and adolescents. Jornal de pediatria. 2006; 82(5):325-34.

4. Sipponen $\mathrm{P}$, Maaroos $\mathrm{H}-\mathrm{I}$. Chronic gastritis. Scandinavian journal of gastroenterology. 2015; 50(6):657-67. 
5. Mehmood K, Awan AA, Muhammad N, Hasan F, Nadir A. Helicobacter Pylori prevalence and histopathological findings in dyspeptic patients. Journal of Ayub Medical College Abbottabad. 2014; 26(2):182-5.

6. Koumi A, Filippidis T, Leontara V, Makri L, Panos MZ. Detection of Helicobacter pylori: A faster urease test can save resources. World J Gastroenterol. 2011; 17(3):349-53.

7. Smith SI, Fowora MA, Otegbayo JA, Abdulkareem FB, Omonigbehin EA, Adegboyega $A$, et al. Comparison of PCR with other diagnostic techniques for the detection of $\mathrm{H}$. pylori infection in patients presenting with gastroduodenal symptons in Nigeria. International journal of molecular epidemiology and genetics. $2011 ; 2(2): 178$.

8. S. Brooks Smith AS, RandallL. Perry, Shadi A. Qasem. Helicobacter pylori: To stain or not to stain? American Journal of Clinical Pathology Am J Clin Pathol. 2012; 137(5):733-8.

9. Lee JY, Kim N. Diagnosis of Helicobacter pylori by invasive test: Histology. Annals of translational medicine. 2015; 3(1).

10. Tajalli $R$, Nobakht $M$, Mohammadi-Barzelighi $H$, Agah S, Rastegar-Lari A, Sadeghipour A. The immunohistochemistry and toluidine blue roles for Helicobacter pylori detection in patients with gastritis. Iranian biomedical journal. 2013; 17(1):36.

11. Dixon MF, Genta RM, Yardley JH, Correa P. Classification and grading of gastritis: The updated Sydney system. The American journal of surgical pathology. 1996; 20(10):1161-81.

12. Mizuno S, Miki I, Ishida T, Yoshida M, Onoyama M, Azuma $T$, et al. Prescreening of a high-risk group for gastric cancer by serologically determined helicobacter pylori infection and atrophic gastritis. Digestive Diseases and Sciences. 2010; 55(11):3132-7.

13. de Martel C, Parsonnet J. Helicobacter pylori infection and gender: A meta-analysis of population-based prevalence surveys. Digestive Diseases and Sciences. 2006; 51(12):2292-301.

14. Sonnenberg A, Lash RH, Genta RM. A National Study of Helicobactor pylori Infection in Gastric Biopsy Specimens. Gastroenterology. 2010; 139(6):1894-901. e2.

15. Mhaskar RS, Ricardo I, Azliyati A, Laxminarayan R, Amol B, Santosh W, et al. Assessment of risk factors of Helicobacter pylori infection and peptic ulcer disease. Journal of global infectious diseases. 2013; 5(2):60.
16. Zhu Y, Zhou X, Wu J, Su J, Zhang G. Risk factors and prevalence of Helicobacter pylori infection in persistent high incidence area of gastric carcinoma in Yangzhong city. Gastroenterology Research and Practice. 2014; 2014.

17. Soltani J, Amirzadeh J, Nahedi S, Shahsavari S. Prevalence of helicobacter pylori infection in children, a population-based cross-sectional study in West Iran. Iranian Journal of Pediatrics. 2013; 23(1):13-8.

18. Goh KL, Chan WK, Shiota S, Yamaoka Y. Epidemiology of Helicobacter pylori infection and public health implications. Helicobacter. 2011; 16(s1):1-9.

19. Wang XI, Zhang S, Abreo F, Thomas J. The role of routine immunohistochemistry for Helicobacter pylori in gastric biopsy. Annals of diagnostic pathology. 2010; 14(4):256-9.

20. Malfertheiner P, Megraud F, O'morain CA, Atherton J, Axon AT, Bazzoli F, et al. Management of Helicobacter pylori infection-the Maastricht IV/Florence consensus report. Gut. 2012; 61(5):646-64.

21. Boldt MS, Pereira RD, Barbosa AJ. Histological identification of $\mathrm{H}$. pylori stained by hematoxylineosin and Giemsa: Review for quality control. Jornal Brasileiro de Patologia e Medicina Laboratorial. 2015; 51(2):108-12.

22. Chitkara Y. Upfront special staining for Helicobacter pylori in gastric biopsy specimens is not indicated. American journal of clinical pathology. 2015; 143(1):848.

23. Sakonlaya D, Apisarnthanarak A, Yamada N, Tomtitchong P. Modified toluidine blue: An alternative stain for Helicobacter pylori detection in routine diagnostic use and post-eradication confirmation for gastric cancer prevention. Asian Pac J Cancer Prev. 2014; 15(16):6983-7.

24. Rotimi O, Cairns A, Gray S, Moayyedi P, Dixon M. Histological identification of Helicobacter pylori: comparison of staining methods. Journal of clinical pathology. 2000; 53(10):756-9.

25. S.Red'een, 2 F.Petersson,3 E.T"ornkrantz,1,2 H.Levander,1,2 E.M ${ }^{\circ}$ ardh,1,2 and K. Borch1,2. Reliability of diagnostic tests for helicobacter pylori infection. Gastroenterology Research and Practice. $2011 ; 2011$. 


\begin{tabular}{|c|c|c|c|}
\hline \multicolumn{4}{|c|}{ AUTHORSHIP AND CONTRIBUTION DECLARATION } \\
\hline Sr. \# & Author-s Full Name & Contribution to the paper & Author $=s$ Signature \\
\hline 1 & $\begin{array}{l}\text { Hina Khan } \\
\text { Sadaf Alam }\end{array}$ & $\begin{array}{l}\text { Data acquisition, Drafting the } \\
\text { work. } \\
\text { Critical analysis. }\end{array}$ & \\
\hline 3 & Shahnawaz Khan & Review & \\
\hline 4 & $\begin{array}{l}\text { Mumtaz Khan } \\
\text { Fozia Rauf }\end{array}$ & $\begin{array}{l}\text { Final approval of the version to } \\
\text { be published. } \\
\text { Conception and design. }\end{array}$ & \\
\hline
\end{tabular}

